Portland State University

PDXScholar

$11-12-1976$

\title{
Depression and the Perception of Reinforcement: a Modified Replication
}

Adele Gillis

Portland State University

Follow this and additional works at: https://pdxscholar.library.pdx.edu/open_access_etds

Part of the Mental and Social Health Commons, and the Psychiatry and Psychology Commons Let us know how access to this document benefits you.

Recommended Citation

Gillis, Adele, "Depression and the Perception of Reinforcement: a Modified Replication" (1976).

Dissertations and Theses. Paper 2389.

https://doi.org/10.15760/etd.2386

This Thesis is brought to you for free and open access. It has been accepted for inclusion in Dissertations and Theses by an authorized administrator of PDXScholar. Please contact us if we can make this document more accessible: pdxscholar@pdx.edu. 
AN ABSTRACT OF THE THESIS OF Adele Gillis for the Master of Arts in Psychology presented November 12, 1976.

Title: Depression and the Perception of Reinforcement: A Modified Replication.

APPROVED BY MEMBERS OF THE THESIS COMMITTEE:

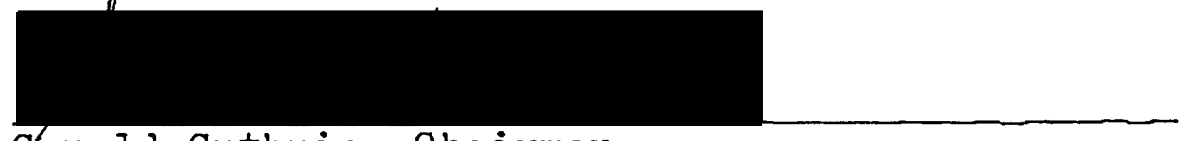

Gerald Guthrie, Chairman

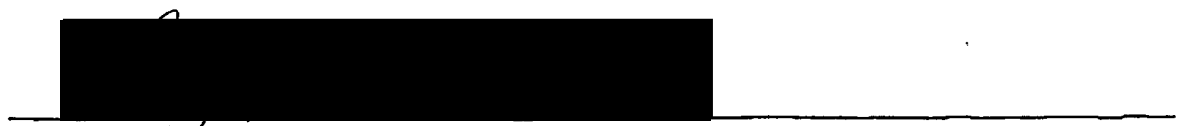

Barry Anderson
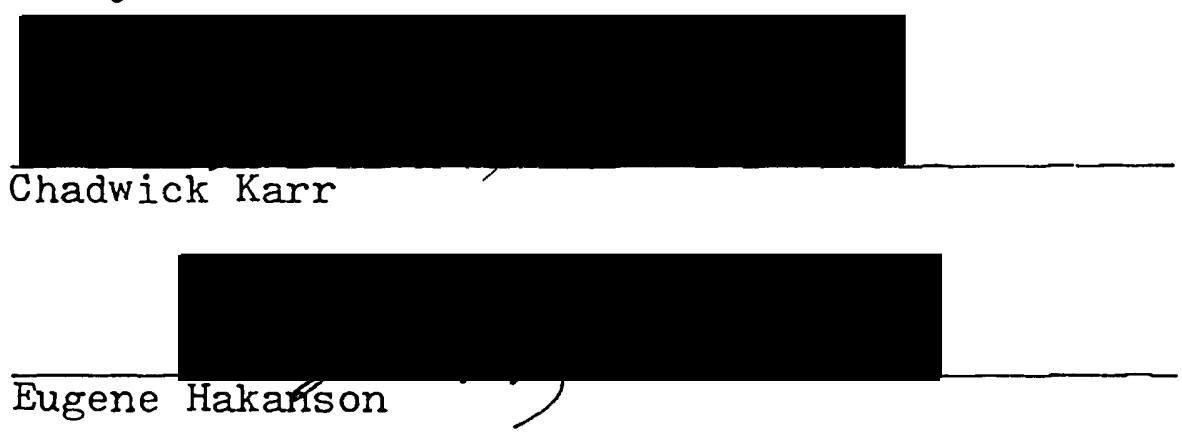

The present study was a modified replication of Miller and Seligman's (1973) study. Expectancy ratings under skill and chance tasks were examined in 51 college students in four groups: depressed high-external, depressed low-external, nondepressed high-external, and nondepressed lowexternal. The major hypotheses predicted that there would be greater association (1) between both magnitude and direction of expectancy change and outcome of the previous trial (success/non-success) with nondepression than with 
depression, under the skill task, (2) between both magnitude and direction of expectancy change and outcome of the previous trial (success/non-success) with low-externality than with high-externality, under the skill task, and (3) between both magnitude and direction of expectancy change and outcome of the previous trial (success/non-success) for low-externality than for high-externality under the skill task and that this would be more evident with nondepression than with depression. None of these hypotheses was confirmed; no significant differences in expectancy ratings among the groups were found. Possible reasons for the failure of the present study to support Miller and Seligman's findings regarding the influence of depression were discussed and suggestions for future research were made. 
DEPRESSION AND THE PERCEPTION OF REINFORCEMENT: A MODIFIED REPLICATION

by

Adele Gillis

A thesis submitted in partial fulfillment of the requirements for the degree of

MASTER OF ARTS

IN

PSYCHOLOGY

Portland State University

1976 
TO THE OFFICE OF GRADUATE STUDIES AND RESEARCH:

The members of the Committee approve the thesis of Adele Gillis presented November 12, 1976.

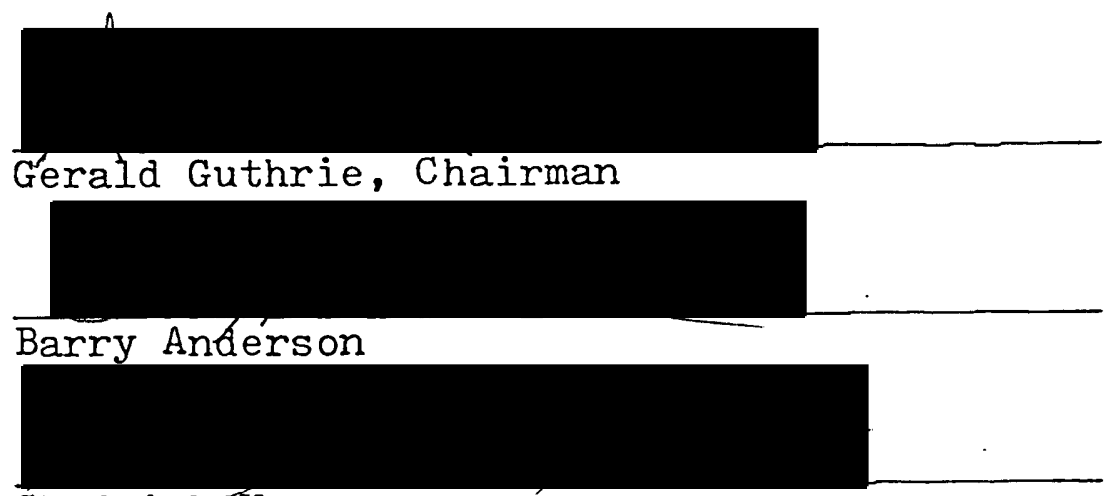

Chadwick Karr

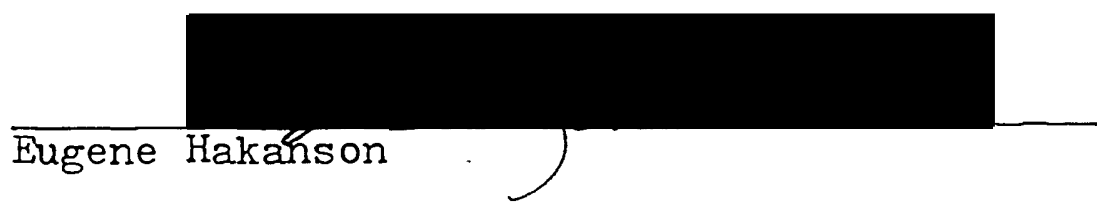

APPROVED ,

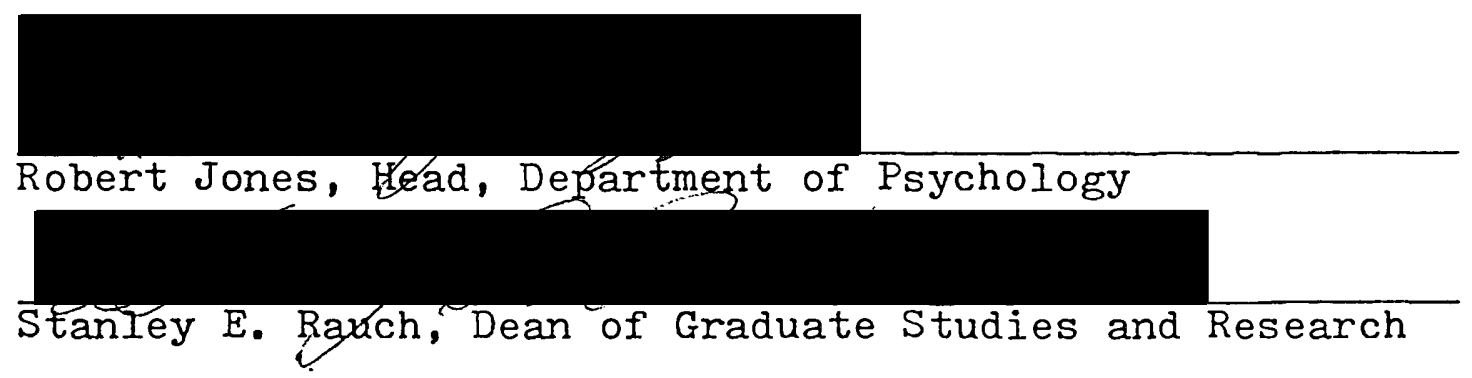




\section{ACKNOWLEDGMENTS}

I would like to extend my appreciation to the members of my thesis committee, Barry Anderson Chadwick Karr, Eugene Hakanson, and in particular, Gerald Guthrie, Chairman, for their cooperation, support and guidance. Special thanks are extended to Barbara Stewart, for assistance with the statistical analysis, James McMullen, for assistance with the experimental apparatus, and all those students who participated in the experiment. 
TABLE OF CONTENTS

PAGE

ACKNOWLEDG EMENTS

iii

LIST OF TABLES

INTRODUCTION

PROBLEM

PROC EDURE

Subjects • • • • • • • • • • 10

Apparatus • • • • • • • • • • 11

Design and Methodology • . • • • • 11

Methods of Analysis . • . . . . 14

DISCUSSION • • • • • . • • • • • • • • 21

REFERENCES • • • • • • • • • • • • • • 25

APPENDIX • . . . • . . . • . . . • • 27 


\section{LIST OF TABLES}

TABLE

PAGE

I Six Hypotheses In Abbreviated Form • • 9

II Means $(\bar{X})$ and Standard Deviations (SD) for 235 Students $(N=235) \cdot \cdot \quad \cdot \quad 15$

III Final $\mathrm{n}$ for Each of the Four Experimental

$$
\text { Groups }(N=51) \cdot \cdot \text { • • • } 16
$$

IV ANOVA On z-Transformed $r_{\mathrm{pb}}{ }^{\circ} \mathrm{s}(\mathrm{N}=51) \cdot .17$

$\mathrm{V}$ ANOVA On $\mathrm{z}$-Transformed $\not \cdot \mathrm{s}(\mathrm{N}=51) \cdot .18$

VI ANOVA On DM \#1: (Difference Between Ex-

$$
\begin{aligned}
& \text { pectancies Given Prior To Trial } 1 \text { and } \\
& \text { Prior To Trial 2) }(\mathrm{N}=51) \text {. . . } 19
\end{aligned}
$$

VII ANOVA On DM \#2 (Final Expectancy Stated

$$
\text { in the Task })(N=51) \cdot . \quad \cdot \quad \cdot 20
$$

VIII. ANOVA On DM. \#3 (Total Amount of Expec-

$$
\text { tancy Change })(N=51) \text {. . . } 21
$$




\section{INTRODUCTION}

From his social learning theory, Rotter (1954) proposed the concept of internal-external locus of control of reinforcement, referring to the degree of perceived contingency between one's"own behavior and reinforcement. The Internal-External (I-E) Scale (Rotter, 1966) distributes subjects along a continuum. Individuals scoring toward the internal end of the scale are described as having the belief that reinforcements are contingent upon their own behavior or attributes. Individuals scoring toward the extermal end of the scale are described as believing that reinforcements are largely the result of fate, chance, luck, or powerful others. The internal-external locus of control is regarded as a generalized expectancy resulting from past reinforcement experiences.

The most commonly used paradigm for demonstrating the behavioral effects of internal-external locus of control is that of skill/chance conditions. James (1957) found that subjects scoring toward the external end of the I-E scale behaved under skill conditions in the same way as subjects overall behaved under chance conditions, i.e., external subjects exhibited significantly more "unusual shifts" (gambler's fallacy) in the skill condition, in which they raised expectancy (for success) after failure and lowered expectancy after success. The prevalence of "unusual shifts" by externals under skill conditions has been one of 
the most consistently replicated findings in the internalexternal Iiterature (Rotter, 1966).

The possible relationship between externality and depression has been investigated by several authors (Abramowitz, 1969; Calhoun, Cheney, and Dawes, 1974; Emmelkamp and Cohen-Kettenis, 1975; Naditch, Gargan, and Michael, 1975). These authors report significant (albeit low) correlations between externality and self-reported depression.' Indirectly supporting this relationship between externality and depression is a study by Butterfield (1964), who found that intro-punitive reactions (placing blame on oneself) increased in frequency as locus of control increased in externality. Noting the conceptual similarity between learned helplessness and externality, Miller and Seligman (1973) have hypothesized a learned helplessness model of depression. Research by Overmeir and Seligman (1967) and Seligman and Maier (1967) has demonstrated that animals exposed to inescapable, unavoidable shock show future deficits in responding to escape shock and have difficulty in learning contingencies between responses and reinforcement even after they respond and reinforcement follows; this phenomenon has been referred to as learned helplessness. Miller and Seligman (1973) suggested that this perceived lack of contingency between response and outcome underlies depression.

Yet, there is speculation by prominent internal- 
external theoreticians associating depression with internality. Phares (1972) postulated that "depressions tend to be associated with people who possess a strong generalized expectancy that outcomes are their own responsibility. This, of course, is suggestive of the internal versus external control of reinforcement variable." Efran (1963) has reported that the tendency to forget (repress) failures was significantly related to internality and Rotter (1966) has interpreted this as indicating that externals are not as likely as internals to blame themselves for their failures, an interpretation which further strengthens the possibility of a relationship between internality and depression. This conflict suggests that there may be a more complex relationship between depression and externality than previously indicated. A possible complicating factor may be the existence of "defensive externals" (Hamsher, Geller, and Rotter, 1968), individuals who describe themselves as externals and are behaviorally defined internals. Defensive externality may be particularly common in depressives, where the self-described externality would reflect the general negativism of depression, rather than a generalized expectancy of the individual.

One way of investigating defensive externality in depressives is to measure both I-E scores and behavior under skill/chance conditions. Such a study was done by Miller and Seligman (1973) in their investigation of de- 
pression and learned helplessness. The authors observed four groups of subjects in both skill and chance tasks: (1) depressed high-external, (2) depressed low-external, (3) non-depressed high-external, (4) non-depressed lowexternal. (Mean scores were used as cut-off points for defining both high and low-external, and depressed and nondepressed subjects.) Three dependent measures were used: (1) difference between expectancies prior to Trial 2 and prior to Trial 1, (2) final expectancy stated, (3) the summed absolute value of difference in expectancies between one trial and the next for all trials in which subjects increased expectancy following positive reinforcement or decreased expectancy following negative reinforcement. The authors"also measured "unusual shifts," which were found tobe rare and did not differentiate between groups.* The major hypothesis (based upon the learned helplessness model), that depressed subjects would show less change in "expectancy following reinforcement in the skill condition than nondepressed subjects, was significantly supported. However, the secondary hypothesis, that high-external sub-jects would show less change in expectancy following reinforcement. in chance and skill than high-internal subjects, was not confirmed; differences in expectancy were in the predicted direction, although they were quite small and * Miller, personal communication. 
non-significant. In discussing the failure of this hypothesis to be confirmed, the authors suggested that the I-E Scale is not a valid measure of internal-external control as measured by expectancy changes in tasks of skill and chance. It is suggested here that the lack of support for the secondary hypothesis regarding locus of control may have been due to the use of mean scores of the I-E Scale as cutoff points for high-and low-externals. Miller and Seligman argue against the validity of the I-E Scale partially on the basis that the Beck Depression Inventory, using a relatively small range of possible scores, was sufficiently sensitive to discriminate depression in their study and thus there should be no need to use extreme I-E scores. However, it has been traditional in the internal-external Iiterature to use extreme scores (Liverant and Scodel, 1960; Phares, Wilson, and Klyver, 1971; Seeman, 1963; Watson and Baumal, 1967). The use of mean scores as cut-off points may also account for the finding of Miller and Seligman that "unusual shifts" were rare and undifferentiated between groups. Since the predictions regarding the behavior of externals under skill/chance conditions are based upon previous internal-external research, it appears more appropriate to utilize extreme I-E scores. It is, therefore, proposed that the Miller and Seligman (1973) study be replicated, utilizing extreme scores in the operational definition of high-and low-external subjects. 


\section{PROBLEM}

The design of this study is a replication of Miller and Seligman (1973), with the modification that extreme I-E scores will be used to define high- and low-external subjects. Two dependent variables are to be used: absolute magnitude of expectancy change and direction of expectancy change relative to the success/non-success outcome of the previous trial. Within each of the following hypotheses, the same predictions are made for each of these two variables. The hypotheses are:

\#1. It is hypothesized that: (a) the magnitude of expectancy change under the skill condition will be greater for low-external (LE) Ss than for high-external (HE) Ss, and $(b)$ the direction of expectancy change under the skill condition will be more consistent with the success/nonsuccess outcome of the previous trial (i.e., expectancy change will be toward success following success, expectancy change will be toward non-success following nonsuccess) for the LE Ss than the HE Ss. These predictions are suggested by the results reported in Rotter (1966). \#2. It is hypothesized that: (a) the magnitude of expectancy change under the skill condition will be greater for non-depressed (D) Ss than for depressed (D) Ss, and (b) the direction of expectancy change under the skill condition will be more consistent with the success/non-success outcome of the previous trial for the $\bar{D}$ Ss than for the DSs. 
These predictions are suggested by the results reported in Miller and Seligman (1973).

\#3. It is hypothesized that externality and depression will interact under the skill condition in such a way that, externality will make a greater difference in both the magnitude and the direction of expectancy change for the $\bar{D}$ Ss than for the D Ss. Therefore, it is predicted that, under the skill condition, the greater positive association both between reinforcement and magnitude of expectancy change, and reinforcement and direction of expectancy change for $\mathrm{LE}$ than for $\mathrm{HE}$, predicted in Hypothesis \#1, will be more evident with the $\bar{D}$ Ss than with the D Ss. This prediction is suggested by the description of "defensive externality" found in Hamsher, Geller, and Rotter (1968).

\#4. An interaction between externality and the skill condition is hypothesized, such that the greater positive association both between reinforcement and magnitude of expectancy change, and reinforcement and direction of expectancy change for $\mathrm{LE}$ than for $\mathrm{HE}$, predicted in Hypothesis \#1, is postulated for the skill condition only. No significant differences in strength of association both between reinforcement and magnitude of expectancy change, and reinforcement and direction of expectancy change for either IE or $\mathrm{HE}$ is predicted under the chance condition.

\#5. An interaction between depression and the skill condition is hypothesized, such that the greater positive 
association both between reinforcement and magnitude of expectancy change, and reinforcement and direction of expectancy change for $\bar{D}$ than for $D$, predicted in Hypothesis $\# 2$, is postulated for the skizl condition only. No significant differences in strength of association both between reinforcement and magnitude of expectancy change, and reinforcement and direction of expectancy change for either $\bar{D}$ or $\mathrm{D}$ is predicted under the chance condition.

\#6. An interaction among externality, depression, and the skill condition is hypothesized, such that the prediction made in Hypothesis \#3, that the greater positive association both between reinforcement and magnitude of expectancy change for LE than for $H E$ will be more evident with the $\bar{D}$ Ss than with the D Ss, is postulated for the skill condition only. No significant differences in strength of association both between reinforcement and magnitude of expectancy change, and reinforcement and direction of expectancy change for any of these traits is predicted under the chance condition.

The above six hypotheses are tabled in abbreviated form in TABLE I below. 
TABLE I

SIX HYPOTHESES IN ABBREVIATED FORM

\begin{tabular}{|c|c|c|}
\hline & $\begin{array}{l}\text { MAGNITUDE OF } \\
\text { EXP. CHANGE (a) }\end{array}$ & $\begin{array}{l}\text { DIRECTION OF } \\
\text { EXP. CHANGE (b) }\end{array}$ \\
\hline $\begin{array}{c}\text { EXTERNAIITY }(\# 1) \\
(E)\end{array}$ & $\begin{array}{l}\text { greater association } \\
\text { between reinf. and } \\
\text { mag. shifts for LE } \\
\text { than } \mathrm{HE} \text {. }\end{array}$ & $\begin{array}{l}\text { greater associa- } \\
\text { tion between re- } \\
\text { inf. \& dir. shifts } \\
\text { for LE than HE. }\end{array}$ \\
\hline $\begin{array}{c}\text { DEPRESSION (\#2) } \\
(D)\end{array}$ & $\begin{array}{l}\text { greater association } \\
\text { between reinf. and } \\
\text { mag. shifts for } \bar{D} \\
\text { than D. }\end{array}$ & $\begin{array}{l}\text { greater associa- } \\
\text { tion between re- } \\
\text { inf. \& dir. shifts } \\
\text { for } \bar{D} \text { than D. }\end{array}$ \\
\hline $\begin{array}{l}E \times D \\
\text { INTERACTION } \\
\qquad(\# 3)\end{array}$ & $\begin{array}{l}\text { the greater assoc. } \\
\text { between reinf. \& } \\
\text { mag. shifts for LE } \\
\text { than HE more evident } \\
\text { with } \bar{D} \text { than D Ss. }\end{array}$ & $\begin{array}{l}\text { the greater assoc. } \\
\text { between reinf. \& } \\
\text { dir. shifts for LE } \\
\text { than } \mathrm{HE} \text { more evi- } \\
\text { dent with } \bar{D} \text { than } \\
\text { D Ss. }\end{array}$ \\
\hline $\begin{array}{c}\text { E X Skill (S) } \\
\text { INTERACTION } \\
(\# 4)\end{array}$ & $\begin{array}{l}\text { hyp. \#1 pertains to } \\
\text { skill condition } \\
\text { only; no difference } \\
\text { between IE and } \mathrm{HE} \\
\text { in chance. }\end{array}$ & $\begin{array}{l}\text { hyp. \#1 pertains } \\
\text { to skill condi- } \\
\text { tion only; no dif- } \\
\text { ference between } \\
L E \text { and } H E \text { in chance }\end{array}$ \\
\hline $\begin{array}{l}p \times S \\
\text { INTERACTION } \\
(\# 5)\end{array}$ & $\begin{array}{l}\text { hyp. \#2 pertains to } \\
\text { skill condition } \\
\text { only, no difference } \\
\text { between } \bar{D} \text { and } D \text { in } \\
\text { chance. }\end{array}$ & $\begin{array}{l}\text { hyp. \#2 pertains } \\
\text { to skill condition } \\
\text { only; no differ- } \\
\text { ence between } \bar{D} \\
\text { and } D \text { in chance. }\end{array}$ \\
\hline $\begin{array}{c}E \times D \times S \\
\text { ENTERACTION } \\
(\# 6)\end{array}$ & $\begin{array}{l}\text { hyp. \#3 pertains to } \\
\text { skill condition } \\
\text { only; no difference } \\
\text { among Ss in chance. }\end{array}$ & $\begin{array}{l}\text { hyp. \#3 pertains } \\
\text { to skill condi- } \\
\text { tion only; no dif- } \\
\text { ference among Ss } \\
\text { in chance. }\end{array}$ \\
\hline
\end{tabular}


PROCEDURE

Subjects

The Beck Depression Inventory (BDI) and Rotter I-E Scale (I-E) were group administered to 195 students in college classes. At that time, volunteers for the experiment were solicited and twenty-six (26) subjects (Ss) were tested individually. These $26 \mathrm{Ss}$ were readministered the $\mathrm{BDI}$ and I-E immediately following individual testing.

Thereafter, in order to fulfill the requirement of a minimum of ten (10) Ss in each of the four experimental groups, requests for volunteers for the experiment were made in college classes and an additional forty (40) Ss were individually tested. These Ss were also individually administered the BDI and I-E immediately following their testing.

Thus, scores on the BDI and I-E were obtained for 235 students (66 of whom participated in the experiment voluntarily). These scores were obtained in order to compute means and standard deviations, to be used in the operational definition of the four experimental groups: depressed highexternal (DHE), depressed low-extermal (DLE), nondepressed

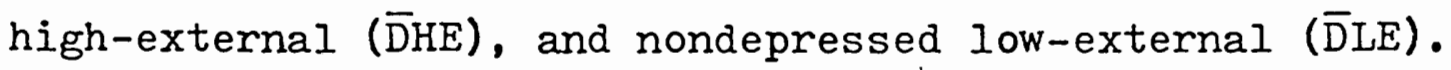
of the $66 \mathrm{Ss}$ individually tested, the scores of $10 \mathrm{Ss}$ on the BDI or I-E did not meet the criteria for inclusion in one of the four experimental groups; 2 Ss guessed the experimenter-controlled nature of the tasks and 3 Ss were 
unable to complete the experiment because of equipment failure in one of the tasks. Thus, the data of 15 out of the 66 Ss individually tested were excluded from the anaiysis, leaving a total of $51 \mathrm{Ss}$ in the final experimental sample $(N=51)$.

\section{Apparatus}

The apparatus used included the Beck Depression Inventory ( $B D I)$, the Rotter I-E Scale ( $I-E$ ), equipment for the chance and skill tasks as described by Miller and Seligman (1973), record sheets, and pencils.

The chance task consisted in guessing whether the letter $\mathrm{X}$ or 0 would appear on the screen of a slide projector; although Ss were told that their occurrence was randomly arranged, it was actually covertly controlled by the experimenter.

The skill task consisted in raising a wooden platform in such a way that a steel bearing placed at the top of the platform would not fall; again, the experimenter covertly controlled success and non-success.

\section{Design and Methodology}

The Ss were randomly assigned to either the skillchance or chance-skill task order. All Ss were given ten (10) trials under each of the two conditions. The experimenter read the instructions for the first task (either skill or chance depending on task order) im- 
mediately prior to individual testing; the same instructions, with minor modifications, as given in Miller and Seligman (1973), were used.

The instructions for the skill task were:

This task is designed to see how well you can succeed in raising the platform without letting the ball fall off and also to see how accurate you are in estimating your success. The object of the task is for you to try by pulling this string to raise the ball on the platform as high as possible before the ball drops off. You will be given 10 trials. The apparatus is built with a slight tilt forward so that the ball is more likely to fall off the platform the higher it is raised. Of course, if you raise the platform very quickly, the ball cannot drop off because of its momentum. Therefore, the platform must be raised slowly. Now, in order to be successful, you must raise the platform and the ball to this level (the experimenter demonstrates). Are there any questions?

The instructions for the chance task were:

This task is designed to see how well you can do at telling me before hand which of the two kinds of slides will appear next on the screen and also to see how accurate you are in estimating your success. In this projector we have a number of slides marked with either an $X$ or an 0 . These slides are divided into groups of five. Each set of five slides was shuffled before being placed in the projector. There are not necessarily the same number of $X_{s}$ and $O s$ in each set. Before we began, I selected at random one of these sets of five slides and positioned it for projection. You are to tell me whether the first slide in the group is an X or an 0 . After you tell me, I will project the slide onto the screen, and you will then know whether it is an $X$ or an 0 . In this way, we will go through all five slides of the group.

Each set of five slides will constitute one trial. We will continue until we have gone through 10 trials. I.will also be keeping score and will let you know how well you did at the end of each trial.

Now, in order to be successful on a trial, you must get at least four slides right. In other words, four or five siides right out of the five slides in a set will mean that you have succeeded. Any number of slides correct below four will mean that you have not succeeded. Are there any questions? 
The Ss estimated their probabilities of success before each trial, using a scale ranging from 0 (certain failure) to 10 (certain success), inclusive. After it was determined that the $S$ understood the task requirement, the experimenter read the instructions for estimating probability of success (expectancy for future success) and it was specified that feedback on performance would be given; instructions similar to those used by Miller and Seligman (1973) were employed.

Instructions for estimating the probability of success were:

Before each trial, I would like you to estimate how certain you are that you can correctly predict four or five slides out of five (raise the platform to that level without letting the ball fall off). You are to estimate your degree of certainty of success on a scale going from 0 to 10 . For example, if you feel fairly certain that you will succeed, you may rate yourself with a high number such as a 9 or a 10. If you feel moderately sure that you will succeed, you may rate yourself with a number near the center of the scale, such as a 4, 5, or 6. If you feel pretty sure that you will not be successful, you may rate yourself with a low number, such as a or 1 . You may use any number on the scale from 0 to 10 , inclusive. It is important that you select your estimates carefully and that they correspond closely with how certain you really are. They should be an accurate description of the degree to which you really feel that you will or will not succeed. Are there any questions?

Now, before we begin, make an estimate on the 0-10 scale as to what you think your likelihood is of success on the first trial.

After completion of the first task, the instructions for the second task were read, and the $S$ was reminded of the method for estimating his probability of success. 
Success and non-success was controlled by the experimenter in order to insure that all Ss had the same schedule of reinforcement. The same 50\% reinforcement schedule was used for both tasks. Trials 1 and 10 were positively reinforced (successful) trials, in order that the procedure of Miller and Seligman (1973) would be replicated. The sequence of reinforcement on Trials 2-9 was randomly determined for both tasks and the same random order was used for all Ss.

Following completion of the second task, each $S$ was administered the BDI and I-E (regardless of whether they had previously taken it). On the basis of the scores obtained during this administration, those Ss whose scores met the criteria were assigned to one of the following groups: DHE, DLE, $\bar{D} H E$, or $\bar{D} L E$.

During scoring of the two questionnaires, each $S$ was asked whether he had any impressions or perceptions of either of the two tasks (in order to determine whether or not the $S$ had discovered the experimenter-controlled nature of either of the tasks) and their responses were recorded, if noteworthy. Each $S$ was then fully de-briefed regarding the nature of the experiment and the two questionaires.

\section{Methods of Analysis}

The means and standard deviations obtained for the BDI and the I-E Scale for the 235 students administered the two questionnaires are presented in TABLE 2 below. 
TABLE II

MEANS $(\bar{X})$ AND STANDARD DEVIATIONS ( $(\mathrm{SD})$

FOR 235 STUDENTS $(N=235)$

\begin{tabular}{|l|l|l|}
\hline & BDI & $I-E$ \\
\hline $\bar{X}$ & 5.33 & 9.62 \\
\hline$S D$ & 4.57 & 4.11 \\
\hline
\end{tabular}

On the basis of the BDI mean for these students, depressed Ss were defined as those scoring 6 or above, nondepressed as those scoring 4 or below. In the operational definition of high- and low-external Ss, one-third (1/3) of the standard deviation was added to, or subtracted from the mean; thus, high-external Ss were defined as those scoring 11 (10.99) or above, low-external as those scoring 8 (8.25) or below.

In order to determine the degree of association between the BDI and the I-E Scale, the correlation coefficient was found to be +.304 , and significant $(<.01$, $d f=233)$.

A total of 66 Ss $(N=66)$ participated in the experiment. All of these Ss were administered the BDI and I-E immediately following completion of the two tasks. Of these Ss, $26(n=26)$ had also previously taken the two questionnaires, during group administration; the time interval between these administrations varied between two days and ten days, but was most frequently one week. Testretest reliability coefficients for both the BDI and I-E 
were computed using the two administration scores of these 26 Ss. The reliability coefficient for the BDI was found to be +.82 , and significant $(<.001, \mathrm{df}=24)$; the reliability coefficient for the I-E was found to be +.92 , and significant $(<.001, \mathrm{df}=24)$.

The data of $51 \mathrm{Ss}(\mathrm{N}=51)$ who participated in the experiment were used in the final analysis. The number of Ss within each of the four experimental groups is given in TABIE III below.

\section{- TABIE III}

FINAI $n$ FOR EACH OF THE FOUR EXPERIMENTAL GROUPS $\quad(N=51)$

\begin{tabular}{|c|c|c|c|c|}
\hline & DHE & DIE & $\overline{\bar{D} H E}$ & $\overline{\mathrm{D}} \mathrm{LE}$ \\
\hline $\mathrm{n}$ & 12 & 10 & 10 & 19 \\
\hline
\end{tabular}

The point-biserial correlation coefficient $\left(\mathrm{r}_{\mathrm{pb}}\right)$ was computed in order to determine the degree of association between absolute magnitude of expectancy shift and the outcome of the previous trial (success/non-success) across the 10 trials for each task for every $S$; thus, 102 pointbiserial correlation coefficients were calculated. These correlation coefficients were than transformed to $z$-scores. Using the $z$-transformed $\mathrm{r}_{\mathrm{pb}}$ 's, a $2 \times 2 \times 2$ Analysis of Variance (ANOVA) with repeated measures on the last factor (task) and unweighted means for unequal n's was performed on the data of these $51 \mathrm{Ss}$. A summary table of this ANOVA is presented in TABLE IV below. None of the $F$ ratios was found 
to be significant.

TABLE IV

ANOVA ON $\mathrm{z}$-TRANSFORMED

$r_{\mathrm{pb}} \cdot \mathrm{s} \quad(\mathrm{N}=51)$

\begin{tabular}{|l|c|c|c|c|}
\hline Source & \multicolumn{1}{|c|}{ SS } & df & MS & $F$ \\
\hline Between Ss & 306.9233 & 50 & & \\
\hline A (depression) & 0.0150 & 1 & 0.0150 & 0.0022 \\
\hline B (I-E) & 0.1966 & 1 & 0.1966 & 0.0301 \\
\hline$A B$ & 0.0292 & 1 & 0.0292 & 0.0033 \\
\hline Ss w/i grp. & 306.6825 & 47 & 6.5252 & \\
\hline Within Ss & 74.7511 & 51 & & \\
\hline C (task) & 0.1121 & 1 & 0.1121 & 0.0709 \\
\hline AC & 0.1490 & 1 & 0.1490 & 0.0942 \\
\hline BC & 0.2350 & 1 & 0.2350 & 0.1486 \\
\hline ABC & 0.0490 & 1 & 0.0490 & 0.0311 \\
\hline DxSs w/i grp. & 74.2483 & 47 & 1.5811 & \\
\hline
\end{tabular}

The phi coefficient $(\varnothing)$ was computed in order to determine the degree of association between direction of shift in expectancy ratings and outcome of previous trial (success/non-success) across the 10 trials for each task for every S; thus, 102 phi coefficients were calculated. These coefficients were then transformed to z-scores. Using the $z$-transformed phi coefficients; a $2 \times 2 \times 2$ ANOVA with repeated measures on the last factor (task) and unweighted means for unequal $n^{\prime} s$ was performed on the data of the $51 \mathrm{Ss}$. A summary table of this ANOVA is presented in TABLE $V$ below. None of the $F$ ratios was found to be significant. 
TABLE V

ANOVA ON $\mathrm{z}$-TRANSFORMED

$\varnothing \cdot s(N=51)$

\begin{tabular}{|l|r|r|r|c|}
\hline Source & \multicolumn{1}{|c|}{ SS } & \multicolumn{1}{c|}{$\mathrm{df}$} & \multicolumn{1}{c|}{$\mathrm{MS}$} & $\mathrm{F}$ \\
\hline Between Ss & 5885.9310 & 50 & & \\
\hline A (depression) & 0.8257 & 1 & 0.8257 & 0.0065 \\
\hline $\mathrm{B}(I-E)$ & 0.4084 & 1 & 0.4084 & 0.0032 \\
\hline $\mathrm{AB}$ & 0.5352 & 1 & 0.5352 & 0.0043 \\
\hline Ss w/i grp. & 5884.1602 & 47 & 125.1950 & \\
\hline Within Ss & 1359.2557 & 51 & & \\
\hline $\mathrm{C}$ (task) & 4.5141 & 1 & 4.5141 & 0.1569 \\
\hline $\mathrm{AC}$ & 0.8964 & 1 & 0.8964 & 0.312 \\
\hline $\mathrm{BC}$ & 1.4081 & 1 & 1.4081 & 0.0489 \\
\hline $\mathrm{ABC}$ & 0.5831 & 1 & 0.5831 & 0.0203 \\
\hline $\mathrm{CxSs} w / i$ grp. & 1351.8551 & 47 & 28.7630 & \\
\hline
\end{tabular}

The three dependent measures utilized by Miller and Seligman (1973) were also computed for the present data. These three measures are: DM (Dependent Measure) \#1 --the difference between expectancies given prior to Trial 1 and prior to Trial 2; DM \#2 --the final expectancy stated in the task; DM \#3 --total amount of expectancy change (obtained by summing the absolute value of the difference in expectancies between one trial and the next for all trials in which the $S$ increased expectancy following a success or decreased expectancy following a non-success).

A $2 \times 2 \times 2$ ANOVA with repeated measures on the last factor (task) and unweighted means for unequal n's was calculated using the data of DM \#1 for all 51 Ss. A summary 
table of this ANOVA is given in TABLE VI below. None of the $F$ ratios was found to be significant.

\section{TABLE VI}

ANOVA ON DM \#1 (DIFFERENCE BETWEEN EXPECTANCIES GIVEN PRIOR TO TRIAL 1 AND PRIOR TO TRIAI 2) $\quad(N=51)$

\begin{tabular}{|c|c|c|c|c|}
\hline Source & SS & $d f$ & MS & $F$ \\
\hline Between Ss & 5271.7621 & 50 & & \\
\hline A (depression) & 7.5431 & 1 & 7.5431 & 0.0674 \\
\hline$B(I-E)$ & 0.6310 & 1 & 0.6310 & 0.0056 \\
\hline$\underline{A B}$ & 3.2865 & 1 & 3.2865 & 0.0294 \\
\hline Ss w/i grp. & 5260.3012 & 47 & 111.9213 & \\
\hline Within Ss & 2030.3662 & 51 & & \\
\hline $\mathrm{C}$ (task) & 54.0223 & 1 & 54.0223 & 1.2961 \\
\hline$\underline{A C}$ & 2.4270 & 1 & 2.4270 & 0.0582 \\
\hline$B C$ & 11.0379 & 1 & 11.0379 & 0.2651 \\
\hline$A B C$ & 3.6958 & 1 & 3.6958 & 0.0891 \\
\hline CxSs w/i grp. & 1959.1831 & 47 & 41.6847 & \\
\hline
\end{tabular}

A $2 \times 2 \times 2$ ANOVA with repeated measures on the last factor (task) and unweighted means for unequal $n$ 's was calculated using the data of DM \#2 for all 51 Ss. A summary table of this ANOVA is given in TABLE VII below. None of the E ratios was found to be significant. 
TABLE VII

ANOVA ON DM \#2 (FINAL EXPECTANCY STATED

IN THE TASK $)(\mathrm{N}=51)$

\begin{tabular}{|l|r|r|r|r|}
\hline Source & \multicolumn{1}{c|}{ SS } & \multicolumn{1}{c|}{$\mathrm{df}$} & \multicolumn{1}{c|}{ MS } & \multicolumn{1}{c|}{$\mathrm{F}$} \\
\hline Between Ss & 45231.9643 & 50 & & \\
\hline A (depression) & 0.2149 & 1 & 0.2149 & 0.0002 \\
\hline B (I-E) & 3.9065 & 1 & 3.9065 & 0.0041 \\
\hline$A B$ & 0.4025 & 1 & 0.4025 & 0.0004 \\
\hline Ss w/i grp. & 45227.4403 & 47 & 962.2921 & \\
\hline Within Ss & 5495.6832 & 51 & & \\
\hline C (task) & 270.4831 & 1 & 270.4831 & 2.4378 \\
\hline AC & 10.2179 & 1 & 10.2179 & 0.0921 \\
\hline BC & 0.0482 & 1 & 0.0482 & 0.0004 \\
\hline ABC & 0.1167 & 1 & 0.1167 & 0.0011 \\
\hline CxSs w/i grp. & 5214.7865 & 47 & 110.9530 & \\
\hline
\end{tabular}

A $2 \times 2 \times 2$ ANOVA with repeated measures on the last factor (task) and unweighted means for unequal n's was calculated using the data of DM \#3 for all 51 Ss. A summary table of this ANOVA is given in TABLE VIII below. None of the F ratios was found to be significant. 
TABLE VIII

ANOVA ON DM \#3 (TOTAL AMOUNT OF EXPECTANCY

CHANGE $) \quad(N=51)$

\begin{tabular}{|l|r|r|r|c|}
\hline Source & \multicolumn{1}{|c|}{ SS } & df & \multicolumn{1}{c|}{ MS } & \multicolumn{1}{c|}{$F$} \\
\hline Between Ss & 74073.6421 & 50 & & \\
\hline A (depression) & 144.5111 & 1 & 144.5111 & 0.0921 \\
\hline B.(I-E) & 12.1161 & 1 & 12.1161 & 0.0072 \\
\hline$A B$ & 2.9721 & 1 & 2.9721 & 0.0019 \\
\hline Ss w/i grp. & 73914.0441 & 47 & $1572 / 6402$ & \\
\hline Within Ss & 14498.3626 & 51 & & \\
\hline C (task) & 321.9651 & 1 & 321.9651 & 1.0725 \\
\hline AC & 91.1910 & 1 & 91.1910 & 0.3052 \\
\hline BC & 39.8332 & 1 & 39.8332 & 0.1333 \\
\hline ABC & 0.7151 & 1 & 0.7151 & 0.0024 \\
\hline CXSs w/i grp. & 14044.6592 & 47 & 298.8225 & \\
\hline
\end{tabular}

\section{DISCUSSION}

The results of the present study fail to support any of the hypotheses made. No significant differences among any of the four groups (DHE, DLE, $\bar{D} H E, \bar{D} L E$ ). were found; that is, neither depression nor externality had differential effects upon expectancy ratings in either of the two tasks. The present study thus fails to replicate the findings of Miller and Seligman (1973) regarding the influence of depression upon expectancy ratings under the skill condition.

The lack of significant differences between highand low-external groups is consistent with the results of Miller and Seligman and provides further, indirect support 
for the argument that the I-E Scale is not a valid measure of locus of control as measured by expectancy changes in tasks of skill and chance.

However, the lack of significant differences between depressed and nondepressed groups contradicts Miller and Seligman, whose results supported their hypothesis that depressed Ss perceive reinforcement as more response independent than nondepressed Ss in situations where reinforcement is response dependent, as measured by expectancy ratings in the skill-chance tasks.

One possible explanation for this failure to replicate regarding the depression variable would be that the present study-failed to produce the same effect.with the experimental manipulations in the skill-chance tasks as Miller and Seligman. However, t-tests between mean expectancy ratings for the skill-chance conditions within each group were found to be highly significant for all groups (see Appendix A), indicating that the Ss'did indeed perceive the two tasks differentially and confirming the self-reports of Ss, who stated that they had perceived the chance task as chance and the skill task as skill. Furthermore, Wilcoxon sign-tests (see Appendix B) for differences between the skill-chance tasks within each group on the three dependent measures utilized by Miller and Seligman yielded significant results in all but four cases (DM\#1--DHE, $\bar{D} H E ; D M \# 3$ $--\bar{D} H E, D H E)$. Thus, it appears that the experimental manipulations in skill-chance tasks made in the present study produced the 
same effect as in Miller and Seligman.

A more likely explanation for the failure of the present study to support Miller and Seligman's findings regarding depression is found in the differences in depth of depression between the Ss tested in this study and those tested by Miller and Seligman. The Ss tested by Miller and Seligman were significantly more depressed than those tested in the present study in all but the $\bar{D} L E$ group (see Appendix C). Miller and Seligman found that the depth of depression was significantly negatively correlated with two of the three dependent measures taken (DM \#1 and DM \#2) and concluded that increasing depth of depression was associated with lower expectancy changes in the skill task.

Given the extremely low mean depression score found for the 235 college students tested in this study (5.33) and the structure of the BDI, the use of the mean as a cutoff score for defining depressed and nondepressed. Ss produced the result that a $S$ responding to even two of the items on the BDI (e.g., $\underline{K}(d)$ "I don't get irritated at all at the things that used to irritate me," and $\underline{S}(d)$ "I have lost more than 15 pounds") would be defined as depressed in the present study, yet it is certainly questionable how much the perceptions of such a $S$ would differ from those of a $S$ responding to only one of those items, and consequently defined as nondepressed.

The present study dealt with depths of depression too 
slight to produce any inter-group differences. Perhaps the BDI requires a greater depth of depression than found in this sample in order to discriminate between depressed and nondepressed Ss. Future research could investigate this possibility, by testing a sample that is substantially more depressed but similar in all other respects; perhaps such a sample could be obtained by testing students who are seeking professional help for depression at college counseling centers, etc. 
REFERENC ES

Abramowitz, Stephen I. "Locus of Control and Self-reported Depression among College Students," Psych. Reports, $1969,25,149-150$.

Butterfield, Earl C., "Locus of Control, Test Anxiety, Reactions to Frustration, and Achievement Attitudes," J. Pers., $1964,32,355-370$.

Calhoun, Lawrence G., Cheney, Thomas, and Dawes, A. Stephen, "Locus of Control, self-reported Depression, and Perceived Causes of Depression," J. Cons. and Clin. Psych., $1974,42,736$.

Efran, J. S., "Some Personality Determinants of Memory for Success and Failure," Unpublished Doctoral Dissertation, Ohio State University, 1963, as cited in Rotter (1966).

Emmelkamp, Paul, and Cohen-Kettenis, Peggy T., "Relationship of Locus of Control to Phobic Anxiety and Depression," Psych. Reports, 1975, 36, 390.

Hamsher; J. Herbert, Geller; Jesse D., and Rotter, Julian B., "Interpersonal Trust, Internal-external Control, and the Warren Commission Report," J. Pers. \& Soc. Psych., $1968,9,210-215$.

James, W. H., "Intermal versus External Control of Reinforcement As a Basic Variable in Learning Theory, "UnpubIished Doctoral Dissertation, Ohio State University, 1957, as cited in Rotter (1966).

Iiverant, Shephard, and Scodel, Alvin, "Internal and External Control as Determinants of Decision Making Under Conditions of Risk," Psych. Reports, 1960, 7, 59-67.

Miller, William R., and Seligman, Martin E. P., "Depression and the Perception of Reinforcement," J."Abn. Psych.", 1973, 82, 62-73.

Naditch, Murray P., Gargan, Margaret A., and Michael, Iaurie B., "Denial, Anxiety, Locus of Control, and the Discrepancy Between Aspirations and Achievements as Components of Depression," J.Abn. Psych.., 1975, $84,1-9$.

Phares, E. Jerry, Wilson, Kenneth G., and Klyver, Nels on W., "Internal-external Control and the Attribution of Blame Under Neutral and Distractive Conditions, J.Pers.\& Soc. Psych., 1971, 18, 185-188. 
Phares, E. Jerry, "A Social Leaming Theory Approach to Psycho-pathology," Applications of a Social Learning Theory of Personality, Rotter, J. B., Chance, J.E., and Phares, e. Jerry (eds.), New York: Holt, Rinehard, and Winston, Inc., 1972, 436-469.

Rotter, Julian B., Social Learning and Clinical Psychology, N. J.: Prentice-Hall, 1954.

Rotter, Julian B., "Generalized Expectancies for Internal versus External Control of Reinforcement," Psycho. Mono., 1966, 80, No. 1 .

Seeman, Melvin, "Alienation and Social Learning in a Reformatory," Am. J. Soc., 1963, 69, 270-284.

Watson, David, and Baumal, Evelyn, "Effects of Locus of Control and Expectation of Future Control upon Present Performance," J. Pers., \& Soc. Psych., 1967, 6, 212215. 
APPENDIX A

\begin{tabular}{|c|c|c|c|c|c|c|c|c|}
\hline & \multicolumn{2}{|c|}{$\mathrm{DHE}$} & \multicolumn{2}{|c|}{ DLE } & \multicolumn{2}{|c|}{$\overline{\mathrm{D} H E}$} & \multicolumn{2}{|c|}{ DLE } \\
\hline & $S$ & $\mathrm{C}$ & $S$ & C & $S$ & $C$ & $S$ & $\mathrm{C}$ \\
\hline$\overline{\bar{x}}$ & 8.42 & 4.11 & 8.11 & 3.75 & 8.50 & 3.88 & 8.41 & 3.78 \\
\hline$t$ & \multicolumn{2}{|c|}{$+16.36 *$} & \multicolumn{2}{|c|}{$+14.18^{*}$} & \multicolumn{2}{|c|}{$+30.84 *$} & \multicolumn{2}{|c|}{$+25.41 *$} \\
\hline
\end{tabular}

Mean $(\bar{X})$ expectancy ratings uncter skill $(S)$ and chance (C) tasks for each of the four groups and $t$-tests for differences between $\bar{x}$ ratings under $S$ and $\mathrm{C}$ for each of the four groups. ( $\mathrm{d} f=8$; *sig. $<.002$ two-tail.)

APPENDIX B

\begin{tabular}{|c|c|c|c|c|}
\hline & DHE & DLE & $\overline{\mathrm{D}} \mathrm{HE}$ & $\bar{D} L E$ \\
\hline DM \#1 & $\begin{array}{l}16 \\
\left(n^{\prime}=7\right)\end{array}$ & $\begin{array}{l}0^{* * *} \\
\left(n^{\prime}=9\right)\end{array}$ & $\begin{array}{l}13.5 \\
\left(n^{\circ}=7\right)\end{array}$ & $\begin{array}{l}19.5^{* *} \\
\left(n^{\prime}=16\right)\end{array}$ \\
\hline DM \#2 & $\begin{array}{l}3 \cdot 5^{* * *} \\
\left(n^{\prime}=11\right)\end{array}$ & $\begin{array}{l}7 \cdot 5^{*} \\
\left(n^{\prime}=10\right)\end{array}$ & $\begin{array}{l}0^{* * *} \\
\left(n^{*}=9\right)\end{array}$ & $\begin{array}{l}0^{* * *} \\
\left(n^{*}=19\right)\end{array}$ \\
\hline DM \#3 & $\begin{array}{l}17 \\
\left(n^{\prime}=11\right)\end{array}$ & $\begin{array}{l}0^{* * *} \\
\left(n^{*}=9\right)\end{array}$ & $\begin{array}{l}22 \\
\left(n^{\prime}=10\right)\end{array}$ & $\begin{array}{l}31^{* * *} \\
\left(n^{*}=19\right)\end{array}$ \\
\hline
\end{tabular}

Wilcoxon sign-tests for differences between skill-chance conditions within each of the four groups on the three dependent measures of Miller and Seligman (1973). (***ig. <.01 two-tail; **sig. $<.02$ two-tail; *sig. $<.05$ two-tail. $) \quad\left(\mathrm{n}^{\prime}=\right.$ number of matched pairs.) 


\section{APPENDIX C}

\begin{tabular}{|c|c|c|c|c|c|c|c|c|c|c|}
\hline & \multicolumn{2}{|c|}{$D H E$} & \multicolumn{2}{|c|}{$D L E$} & \multicolumn{2}{|c|}{$\overline{\mathrm{D}} \mathrm{HE}$} & \multicolumn{2}{|c|}{$\bar{D} L E$} & \multicolumn{2}{|c|}{$\begin{array}{l}\text { AII groups } \\
\text { combined }\end{array}$} \\
\hline & M\&S & Present & M\&S & Present & MESS & Present & M\&S & Present & M\&S & Present \\
\hline$\overline{\mathrm{X}}$ & 13.8 & 8.7 & 11.1 & 9.1 & 4.9 & 2.6 & 1.0 & 0.84 & 7.7 & 5.3 \\
\hline$t$ & \multicolumn{2}{|c|}{$+3.21^{* * *}$} & \multicolumn{2}{|c|}{$+1.61 *$} & \multicolumn{2}{|c|}{$+2.48 * *$} & \multicolumn{2}{|c|}{$+0.4 ?$} & \multicolumn{2}{|c|}{$+1.67^{*}$} \\
\hline$d f$ & \multicolumn{2}{|c|}{19} & \multicolumn{2}{|l|}{17} & \multicolumn{2}{|c|}{17} & \multicolumn{2}{|c|}{26} & \multicolumn{2}{|r|}{7} \\
\hline
\end{tabular}

Mean $(\bar{X})$ depression scores for the four groups for Miller and Seligman (M\&S) and the present study, and t-tests for differences between $\bar{X}$ scores for Miller and...Seligman's $S$ s and those tested in the present study; (** sig. $<.01$ two-tail; **sig. <.05 two-tail; *sig.<.20 two-tail.) 
APPENDIX D

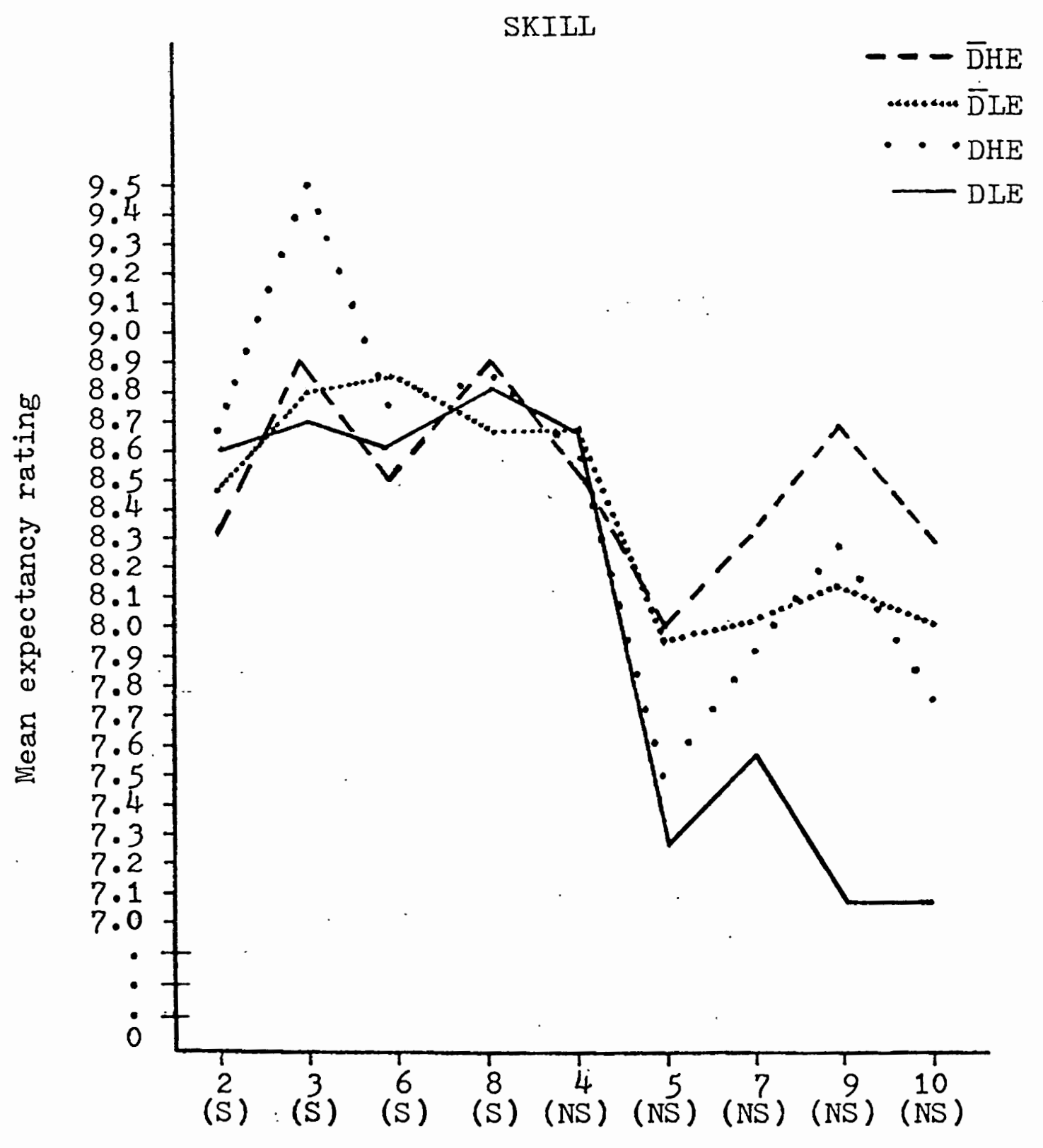

Trial for. which expectancy was given; outcome (Success, Non-Success) of previous trial given in parentheses.

Graph of mean expectancy ratings for each trial under the skill task, for each group. (Trials are clustered according to whether they followed a successful - S trial or a nonsuccessful - NS - trial.) 
APPENDIX E

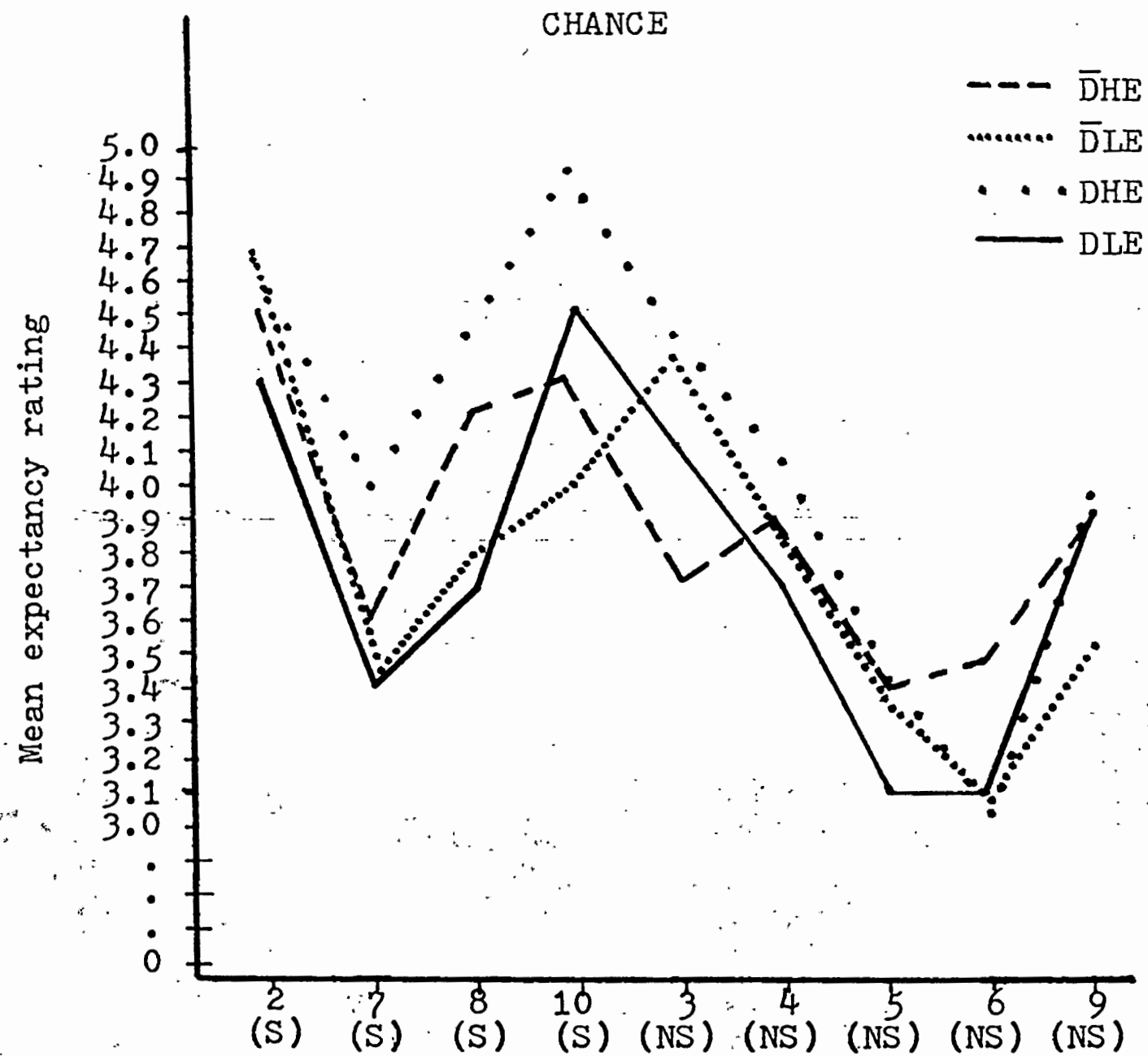

Trial for which expectancy was given; outcome (Success, Non-Success) of previous trial given in parentheses.

Graph of mean expectancy ratings for each trial under the chance task, for each group. (Trials are clustered according to whether they followed a successful - S or a nonsuccessful - NS - trial.) 